\title{
Paclitaxel Resistance by Random Mutagenesis of $\alpha$-Tubulin
}

\author{
Shanghua Yin, ${ }^{1}$ Changqing Zeng,' Malathi Hari,, and Fernando Cabral * \\ ${ }^{1}$ Department of Integrative Biology and Pharmacology, University of Texas Medical School, Houston, Texas
}

Received 30 August 2013; Revised 11 October 2013; Accepted 17 October 2013

Monitoring Editor: George Bloom

Many mammalian $\beta$-tubulin mutations that confer paclitaxel resistance have been characterized, but little is currently known about the role of $\alpha$-tubulin mutations in drug resistance. Previous studies using twodimensional gel electrophoresis showed that $\alpha$-tubulin mutations occur with a frequency equal to $\beta$-tubulin mutations among $\mathrm{CHO}$ cells selected for resistance to paclitaxel but the identities of those mutations are largely unknown. We have now sequenced the major $\alpha$-tubulin gene in several paclitaxel resistant $\mathrm{CHO}$ cell lines with lesions in genomic DNA and identified five mutations that predominately affect the amino terminal part of the protein. We also used random mutagenesis and transfection of $\alpha$-tubulin cDNA to select further paclitaxel resistant mutants in an effort to remove genomic constraints that may limit the diversity of mutations. This approach led to the identification of 16 additional mutations that were distributed throughout the $\alpha$-tubulin sequence. The mutations were confirmed as sufficient to confer resistance by site-directed mutagenesis, and they acted by a mechanism that involved reductions in microtubule assembly. One mutation prevented the acetylation of $\alpha$-tubulin but otherwise produced a phenotype similar to the other mutations. A scan of the literature revealed that a sig-

Additional Supporting Information may be found in the online version of this article.

Abbreviations used: $\alpha$ MEM, alpha modified minimum essential medium; ARG, autoradiogram; GST, glutathione- $S$-transferase; $\mathrm{HA}$, hemagglutinin antigen; MTB, microtubule buffer; ptx, paclitaxel; tet, tetracycline; tTA, tetracycline regulated transactivator; WT, wild-type.

*Address correspondence to: Fernando Cabral, Department of Integrative Biology and Pharmacology, University of Texas Medical School, 6431 Fannin St., Houston, TX 77030, USA.

E-mail: fcabral@uth.tmc.edu

Changqing Zeng's present address is Beijing Institute of Genomics, Chinese Academy of Sciences, 100029, China

Malathi Hari's present address is Division of Hematology/Oncology, University of Michigan Cancer Center, Ann Arbor, MI, 48109, USA

Published online 15 November 2013 in Wiley Online Library (wileyonlinelibrary.com). nificant number of drug resistance mutations overlap or lie close to lesions that have been reported in patients with brain disorders suggesting that alterations in microtubule assembly underlie both cellular resistance and developmental defects. $\odot 2013$ Wiley Periodicals, Inc.

Key Words: drug resistance; microtubules; cancer; vinblastine; taxanes; mitosis; multinucleation; neurological defects

\section{Introduction}

$\mathrm{M}$ icrotubules are important targets for cancer chemotherapeutic drugs. These cytoskeletal structures, formed from heterodimers of $\alpha$ - and $\beta$-tubulin, are needed for many critical cellular functions such as vesicle transport, cell motility, and cell division. Because of their importance for normal cell function, plants and lower organisms have evolved numerous small organic molecules that bind to tubulin and interfere with microtubule assembly and function. These include classical inhibitors such as colchicine which is used in the management of gout, as well as more recently discovered compounds used in cancer therapy. For example, vinblastine and vincristine have been used since the 1950 s to treat hematological malignancies such as leukemia and Hodgkin's lymphoma as well as a wide variety of solid tumors. More recently, taxanes such as paclitaxel and docetaxel have proven to be highly effective for the treatment of breast and ovarian cancer, head and neck tumors, lung cancer, and a number of other diseases. Because of the effectiveness of these agents, the discovery of molecules targeting the microtubule cytoskeleton remains an important area of drug development and many of these new compounds are currently in clinical trials [Dumontet and Jordan, 2010].

Drugs that interfere with microtubule function can be placed into one of two main groups based on their effects on microtubule assembly when present at high concentrations. Many of the compounds including colchicine, vinblastine, and vincristine inhibit the assembly of tubulin into microtubules whereas the second group of compounds including paclitaxel, epothilones, laulimalide, and 
peloruside promote tubulin assembly and stabilize microtubules to disassembly. The fact that both inhibition and stimulation of microtubule assembly is toxic to cells is a reflection of the importance of microtubule behavior in cell division. Microtubules are nucleated at the centrosome, an organelle located near the nucleus, and grow out to the cell periphery by adding subunits to the growing plus-end. Once formed, the microtubules constantly remodel by undergoing stochastic episodes of growth and shrinkage at their plus-ends, a behavior known as dynamic instability [Mitchison and Kirschner, 1984]. When present at low concentrations, all microtubule targeted drugs that have been tested interact with the plusends and suppress dynamic instability [Jordan and Wilson, 2004], a finding that seems at odds with the ability of various drugs to either enhance or inhibit microtubule assembly. However, at higher concentrations these drugs also interact with microtubule minus-ends that are mainly embedded in the centrosome or spindle poles. Microtubule depolymerizing drugs have been shown to increase the frequency at which minus-ends detach from the centrosome [Yang et al., 2010], whereas tubulinpolymerizing drugs decrease that frequency [Ganguly et al., 2010]. Free minus ends have been seen to shorten but not elongate thereby increasing the rate of microtubule turnover [Keating et al., 1997; Yang et al., 2010]. Thus, the effects of the drugs at the minus-end are consistent with their known effects on microtubule assembly.

Cancer patients are generally treated with high concentrations of microtubule agents that interfere with spindle function and inhibit cell proliferation. While this approach has been successful for treating a variety of tumors, patients commonly relapse and become insensitive to further treatment. Although the mechanisms behind the insensitivity of tumor cells to drug treatment in patients is not well understood, cell culture studies have identified many $\beta$-tubulin mutations that are able to confer resistance to the drugs that are commonly used [Huzil et al., 2007; Yin et al., 2012]. Much less is known about the potential role of $\alpha$-tubulin mutations in drug resistance. Early studies suggested that $\alpha$-tubulin mutations are as common as $\beta$-tubulin mutations in $\mathrm{CHO}$ cells selected for paclitaxel resistance [Schibler and Cabral, $1986]$, but to date only one $\alpha$-tubulin mutation from a paclitaxel resistant cell line has been identified by sequencing [Martello et al., 2003]. Several additional mutations in $\alpha$-tubulin have been identified in cell lines selected for resistance to drugs that destabilize microtubules [Hari et al., 2003; Loganzo et al., 2004; Poruchynsky et al., 2004]. To further explore the kinds of $\alpha$-tubulin mutations that can confer drug resistance, we sequenced previously isolated paclitaxel resistant cell lines with mutations in genomic DNA and created new paclitaxel resistant cell lines by random mutagenesis and transfection of an $\alpha$-tubulin cDNA. The properties of the mutants and the locations of the tubulin alterations strongly indicate that the mutations confer paclitaxel resistance by affecting longitudinal and lateral interactions required for microtubule assembly.

\section{Results}

\section{Genomic $\alpha$-Tubulin Mutations are Concentrated near the N-Loop}

Many mammalian $\beta$-tubulin mutations have been described that alter the sensitivity of cells to drugs that can influence microtubule assembly (reviewed in [Huzil et al., 2007; Yin et al., 2012]). Most of the mutations produce similar phenotypes. Thus, cells selected for resistance to paclitaxel (a microtubule stabilizing drug) are frequently seen to exhibit cross resistance to other microtubule stabilizing drugs but enhanced sensitivity to drugs that destabilize microtubules [Schibler and Cabral, 1986; Yin et al., 2010]. Conversely, cells selected for resistance to colcemid or vinblastine are frequently cross resistant to other destabilizing drugs but exhibit enhanced sensitivity to stabilizing drugs [Hari et al., 2003; Minotti et al., 1991]. Paclitaxel resistant cell lines have less microtubule polymer than normal, whereas colcemid and vinblastine resistant cell lines have more polymer than normal suggesting that the mutations are acting by altering the stability of the microtubules [Cabral et al., 1986; Minotti et al., 1991; Cabral, 2008]. Recently, the molecular basis of this altered stability has been traced to the frequency at which microtubules detach from centrosomes and spindle poles [Ganguly and Cabral, 2011]. Microtubule disrupting drugs increase this frequency while microtubule stabilizing drugs decrease the frequency of microtubule detachment [Ganguly et al., 2010; Yang et al., 2010]. Drug resistance mutations oppose these actions; i.e., paclitaxel resistance mutations increase the frequency of detachment and colcemid resistance mutations decrease microtubule detachment.

Mutations in $\beta$-tubulin can also produce resistance by decreasing the affinity of a drug for tubulin. This is most commonly seen in lower organisms that can grow in the haploid state [Sheir-Neiss et al., 1978; Thomas et al., 1985], but has also been observed in mammalian cells selected through multiple rounds of selection. These latter mutants contain lesions in the major expressed $\beta$-tubulin gene ( $\beta 1$-tubulin) and invariably contain additional lesions that may include loss of expression of the remaining wildtype $\beta 1$-tubulin allele [Giannakakou et al., 1997, 2000; Begaye et al., 2011; Kanakkanthara et al., 2011]. These multistep mutants commonly have more limited drug cross-resistance and exhibit higher levels of resistance than cells with mutations that act by altering microtubule assembly.

In contrast to the information about $\beta$-tubulin mutations, little is known about the role of $\alpha$-tubulin mutations in drug resistance. To remedy this situation, we sequenced seven $\mathrm{CHO}$ cell lines that had been selected in a single step 


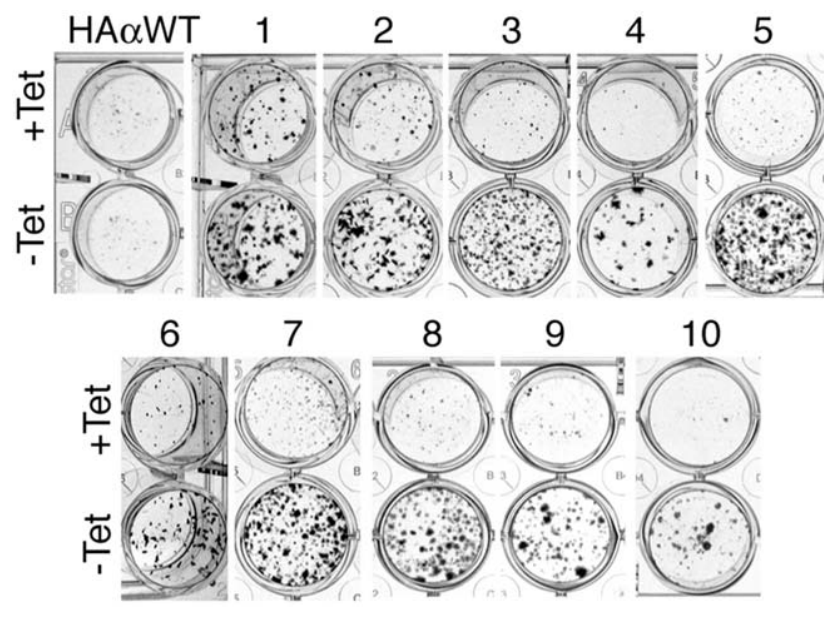

Fig. 1. Tetracycline regulation of paclitaxel resistance in cell lines derived by transfection of randomly mutagenized HA $\alpha 1$-tubulin cDNA. Cells transfected with wild-type HA $\alpha 1-$ tubulin cDNA (HA $\alpha$ WT) or transfected with randomly mutagenized $H A \alpha 1$-tubulin cDNA and selected for paclitaxel resistance (Ptx cell lines 1-10, see Table I) were seeded in duplicate into 24-well dishes and grown for 7 days until visible colonies appeared. To determine whether mutant $H A \alpha 1$-tubulin production was necessary for drug resistance, the medium contained $300 \mathrm{nM}$ paclitaxel in the absence or presence of $1 \mu \mathrm{g} \mathrm{ml}^{-1}$ tetracycline (Tet), an antibiotic used to repress transcription of the transfected cDNA. The dishes were stained with methylene blue and photographed.

Further evidence that the transfected cDNA was responsible for drug resistance came from DNA sequencing. DNA was isolated from 12 random colonies and the integrated HA $\alpha 1$-tubulin cDNA was amplified using primers specific for the $5^{\prime}$ untranslated region of the gene together with a downstream plasmid sequence. A band of the appropriate size for HA $\alpha 1$-tubulin cDNA was obtained and sequencing demonstrated that the cDNAs contained mutations (Table I). Interestingly, two of the mutations identified by random mutagenesis, S48P and K394R, affected residues that were also found to be altered in two of the mutants isolated by classical methods. This overlap suggests that a limited number of amino acids in $\alpha$-tubulin may be involved in generating resistance to paclitaxel.

\section{Double Mutations Confer Resistance Individually}

Although most of the cDNA sequences from paclitaxel resistant clones in the random mutagenesis experiment contained a single mutation, clones Ptx 5, Ptx 7, and Ptx 10 had two mutations and clone Ptx 11 had three. This raised the question of whether each mutation could confer resistance individually or if the combination of mutations was necessary. To resolve this issue, each of the mutations in Ptx 7 and Ptx 10 were introduced into HA $\alpha 1$-tubulin cDNA individually and in tandem by site-directed mutagenesis. Wild type $\mathrm{CHO}$ cells were transfected with these cDNAs

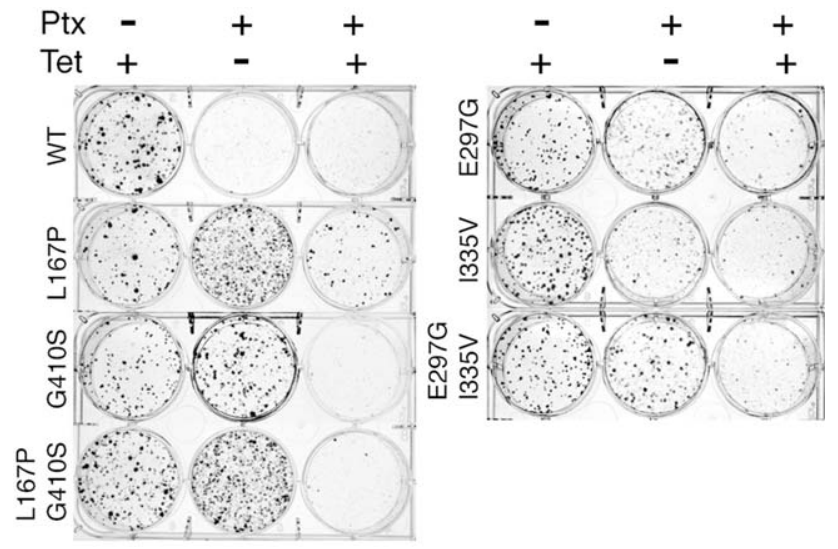

Fig. 2. Double mutations can confer resistance to paclitaxel individually. The double mutations found in cell lines Ptx 7 and Ptx 10 were retested by creating each of the indicated mutations individually and in tandem by site-directed mutagenesis of HA $\alpha 1$-tubulin cDNA. These were transfected into wildtype $\mathrm{CHO}$ cells and compared to cells transfected with a wildtype (WT) HA $\alpha 1$-tubulin cDNA. Stable cell lines were generated by selection for resistance to G418. Each cell line was seeded into triplicate wells of six-well dishes and grown for 7 days in the presence $(+)$ or absence $(-)$ of $300 \mathrm{nM}$ paclitaxel (Ptx) and $1 \mu \mathrm{g} \mathrm{ml}^{-1}$ tetracycline (Tet). Note that the first well in each case was used to control for the number of cells seeded and contained 50-fold fewer cells than the other two but was not treated with paclitaxel. The dishes were stained with methylene blue and photographed.

and tested for their ability to grow in $300 \mathrm{nM}$ paclitaxel in the presence or absence of tetracycline (Fig. 2). The control cells transfected with wild-type HA 1 -tubulin cDNA were only able to form colonies when paclitaxel was absent. In contrast, each of the four mutations identified in these two clones was capable of allowing cell proliferation in paclitaxel when tetracycline was absent indicating that in the clones with multiple mutations, the individual mutations were sufficient to confer resistance. The growth in paclitaxel was inhibited when tetracycline was added to repress transcription of the mutant cDNA. The I335V mutation was the weakest in its ability to allow growth in paclitaxel suggesting that by itself, higher levels of expression are likely to be needed for resistance.

The triple mutant Ptx 11 was not analyzed in a similar manner and we cannot be certain that the mutations are able to confer resistance individually. However, it is likely that the identified mutations are involved in resistance given their proximity to other mutations that have been verified by transfection or reversion analysis. For example, K394R represents the same locus as the K394E mutation in Tax 8-2 (Table I). Even though K394R is a conserved substitution, it has been observed that conserved substitutions in $\beta$-tubulin can alter drug sensitivity and it is likely that a similar situation holds for $\alpha$-tubulin [Wang et al., 2006; Yin et al., 2012]. Similarly, M413I and E414G of Ptx 11 are very close to the G410S mutation of Ptx 7 that was verified by transfection. 


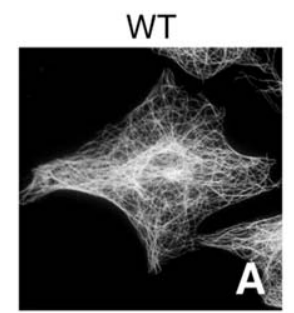

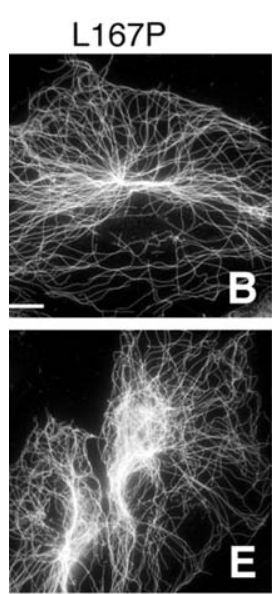

E297G

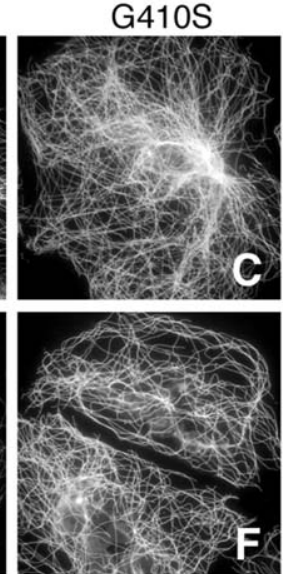

I335V

\section{L167P/G410S}

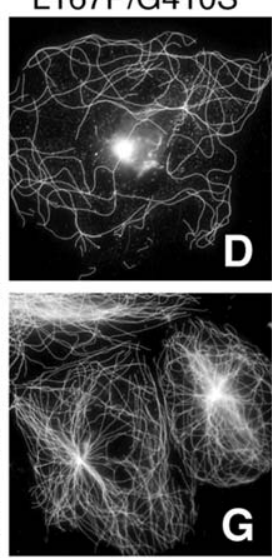

E297G/I335V
Fig. 3. Microtubule immunofluorescence in paclitaxel resistant cell lines. The transfected cell lines described in Fig. 2 were grown for 3 days on glass coverslips without paclitaxel or tetracycline. The cells were then extracted briefly with a microtubule stabilizing buffer, fixed in methanol, and stained with an antibody specific for the HA tag. Bar $=10 \mu \mathrm{m}$.

\section{Paclitaxel Resistance Mutations Alter the Appearance of the Microtubule Network}

To determine whether the mutant HA $\alpha 1$-tubulins were capable of assembly into microtubules and whether they affected microtubule organization, the drug resistant cells were examined by immunofluorescence using an antibody specific for the HA tag. In all cases the HA $\alpha 1$-tubulin was seen to assemble into microtubule arrays. Cells transfected with wild-type HA 1 -tubulin cDNA exhibited normal appearing dense microtubule networks that originated from the centrosomal area located near the nucleus (Fig. 3A).

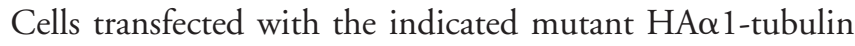
cDNAs had a similar organization of microtubules, but in many cases the network appeared to be less dense (Figs. 3B-3G). This was especially noticeable for cells transfected with the double mutation L167P and G410S (Fig. 3D) indicating that this was a particularly disruptive pair of mutations and/or the cDNA was expressed at a very high level. Similar apparent decreases in microtubule density were seen in the original Ptx cell lines listed in Table I (Supporting Information Fig. S1).

\section{Paclitaxel Resistant Cells Have Reduced Amounts of Microtubule Polymer}

The appearance of the mutant cells in Fig. 3 suggested that they have less microtubule polymer than normal cells. To

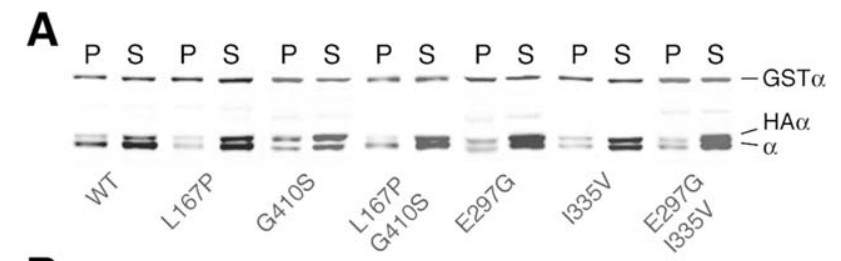

B

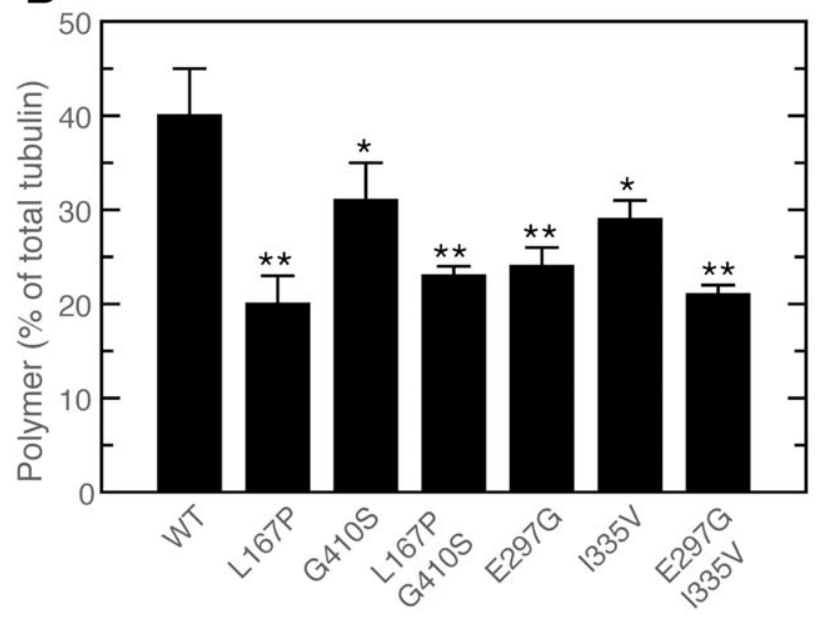

Fig. 4. Tubulin assembly in paclitaxel resistant cells. The mutant transfected cell lines described in Fig. 2 were maintained in $300 \mathrm{nM}$ paclitaxel (no tetracycline) and then incubated overnight without paclitaxel or tetracycline, lysed with a microtubule stabilizing buffer, and centrifuged to separate microtubule polymer in the pellet (P) from soluble tubulin in the supernatant (S). A control cell line (WT) transfected with wild-type HA $\alpha 1-$ tubulin cDNA was maintained in drug-free media throughout. An equal amount of a bacterial cell extract containing glutathione- $S$-transferase-conjugated $\alpha$-tubulin (GST $\alpha$ ) was added to each fraction to control for losses in subsequent steps and the proteins were separated by SDS gel electrophoresis. The proteins were then transferred onto a nitrocellulose membrane and probed with an antibody to $\alpha$-tubulin. An example of such an experiment is shown in (A). HA $\alpha$, transfected wild-type or mutant $H A \alpha$-tubulin; $\alpha$, endogenous $\alpha$-tubulin. Each experiment was run in triplicate three times and the results were quantified as the fraction of tubulin in the pellet $(\mathrm{P})$ relative to the total tubulin $(P+S)$ and expressed as a percentage $(\mathbf{B})$. Significance of the differences from the control (WT) was determined by the student's $t$ test. ${ }^{*}, P<0.05$; ${ }^{* *}, P<0.01$.

confirm this prediction, the relative amounts of polymer were compared in cell lines transfected with wild-type and mutant HA 1 -tubulin cDNAs. The procedure involved lysing cells in a microtubule stabilizing buffer, separating the polymer from soluble tubulin by centrifugation, and quantifying the amount of tubulin in each fraction [Minotti et al., 1991]. The percentage of total tubulin in the microtubule fraction was then calculated for each cell line and the results are summarized in Fig. 4. Western blot analysis demonstrated that wild-type and mutant forms of HA 1 1tubulin were able to assemble and appear in the microtubule fraction $(\mathrm{P})$ in a ratio similar to soluble tubulin (S) indicating that there was little or no preferential assembly of the mutant subunit into, or exclusion from, the 
microtubules (Fig. 4A). However, the relative amount of cellular tubulin appearing in the pellet was reduced in all the mutant cell lines. This result is consistent with a mechanism in which incorporation of the mutant subunit produces resistance by interfering with microtubule assembly [Cabral, 2001, 2008; Ganguly and Cabral, 2011]. The percentage of total $\alpha$-tubulin (endogenous and transfected) assembled into microtubules was about $40 \%$ for cells transfected with wild-type HA 1 1-tubulin (Fig. 4B), a value consistent with previously reported values for tubulin assembly in wild-type or HAß1-tubulin transfected $\mathrm{CHO}$ cells [Minotti et al., 1991; Gonzalez-Garay et al., 1999; Hari et al., 2003]. In contrast, all of the cell lines transfected with mutant $H A \alpha 1$-tubulin exhibited reduced assembly of tubulin ranging from 20 to $31 \%$ of total tubulin thus confirming the visual impression derived from Fig. 3. Similar results were obtained for the original paclitaxel resistant cell lines obtained by transfection where microtubule assembly ranged from 13 to $30 \%$ of total tubulin (Supporting Information Fig. S2). The reduced extent of microtubule assembly in paclitaxel resistant cells carrying mutations in $\alpha$-tubulin is also consistent with results previously reported in paclitaxel resistant cell lines carrying mutations in $\beta$-tubulin [Gonzalez-Garay et al., 1999].

\section{Paclitaxel Resistance Mutations Often Interfere With Cell Division}

Although all mutants grew well in the presence of paclitaxel, it was noted than many of them grew poorly when the drug was removed from the culture medium. This property, called paclitaxel dependence, was previously noted for both $\alpha$-and $\beta$-tubulin mutants and was shown to result from defects in spindle formation and function [Cabral, 1983; Cabral et al., 1983; Schibler and Cabral, 1986]. Although many cell lines with spindle defects become blocked at mitosis, others such as $\mathrm{CHO}$ cells slip through the spindle checkpoint and reenter the next cell cycle as large multinucleated cells [Abraham et al., 1983; Kung et al., 1990]. An example of this behavior is illustrated in Fig. 5 which shows a mixture of untransfected cells and cells that express HA $\alpha 1$-tubulin with an L167P mutation. By appropriately adjusting the antibody concentrations used for immunofluorescence, the transfected cells appear green, yellow, or orange depending on the level of mutant protein produced while the untransfected cells appear red. Thus, transfected and nontransfected cells can be compared directly in the same microscopic field of view. When the cells were cultured without paclitaxel for 3 days, the untransfected (red) wild-type cells had a normal appearance whereas the green transfected cells were frequently larger and contained multiple or oddly shaped nuclei suggestive of cells that had failed to properly segregate chromosomes during mitosis and progressed into G1 phase without dividing (Fig. 5A). In contrast, a similar cell mixture cultured in

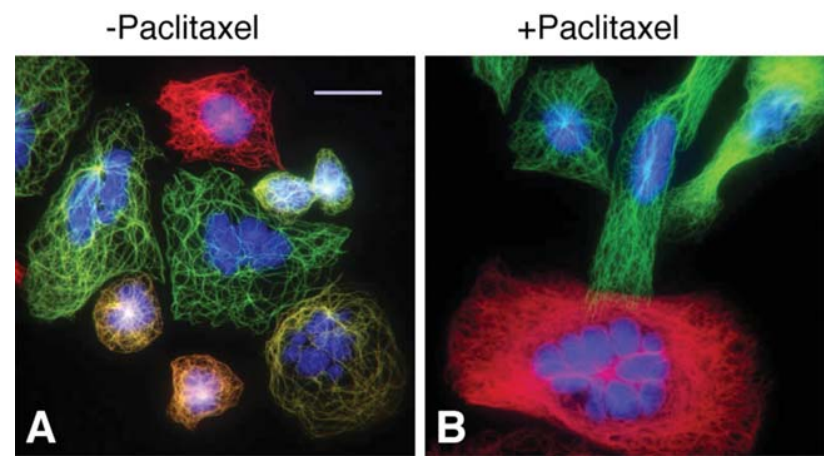

Fig. 5. Paclitaxel dependence of transfected cell lines. A stable G418 resistant cell line expressing HA $\alpha 1$-tubulin cDNA with the L167P mutation was mixed with untransfected cells and grown on glass coverslips for 3 days without (A) or in the presence of $100 \mathrm{nM}$ paclitaxel (B). The cells were extracted with a microtubule stabilizing buffer, fixed in methanol, and stained with antibodies to the HA tag and an Alexa 488conjugated secondary antibody (green), antibodies to $\alpha$-tubulin and an Alexa 594-conjugated secondary antibody (red), and DAPI to stain the DNA (blue). Bar $=20 \mu \mathrm{m}$.

the presence of paclitaxel had normal looking transfected cells (green) but untransfected cells (red) exhibited symptoms of paclitaxel toxicity; i.e., they were larger, had a very dense microtubule network, and contained multiple nuclei characteristic of cells with problems in chromosome segregation and cell division (Fig. 5B). The severity of the mitotic defects noted in the paclitaxel resistant cell lines varied considerably depending on the potency of the mutation and the level of mutant protein production. In general, cells with the lowest assembly of microtubules (see Fig. 4 and Supporting Information Fig. S2) had the most severe defects when paclitaxel was removed from the medium.

\section{Mutation E22K Interferes With Acetylation of $\alpha$-Tubulin Lysine 40}

All of the paclitaxel resistant cell lines had similar phenotypes regardless of the location of their mutations in $\alpha$-tubulin. However, cell line Tax 5-6 was found to have a unique defect that affected its ability to acetylate mutant, but not wild-type, $\alpha$-tubulin. The defect was found using two-dimensional gel electrophoresis of cell extracts (Fig. 6). An autoradiogram of a metabolically labeled wild-type cell extract showed the separation of $\alpha$-tubulin from $\beta$-tubulin and vimentin. In this gel system $\alpha$-tubulin resolves as two spots of similar isoelectric point running with slightly faster mobility than vimentin in the SDS polyacrylamide gel dimension [Boggs and Cabral, 1987; Minotti et al., 1991; Gonzalez-Garay et al., 1999; Hari et al., 2003]. The two spots for $\alpha$-tubulin do not represent alternative gene products but rather appear to result from impurities in SDS and the $\mathrm{pH}$ of the gel buffers that are used (unpublished observations). Both $\alpha$-tubulin spots stain with DM1A, an antibody that recognizes $\alpha$-tubulin, and with $6-11 b-1$, an antibody specific for $\alpha$-tubulin that is acetylated at residue 


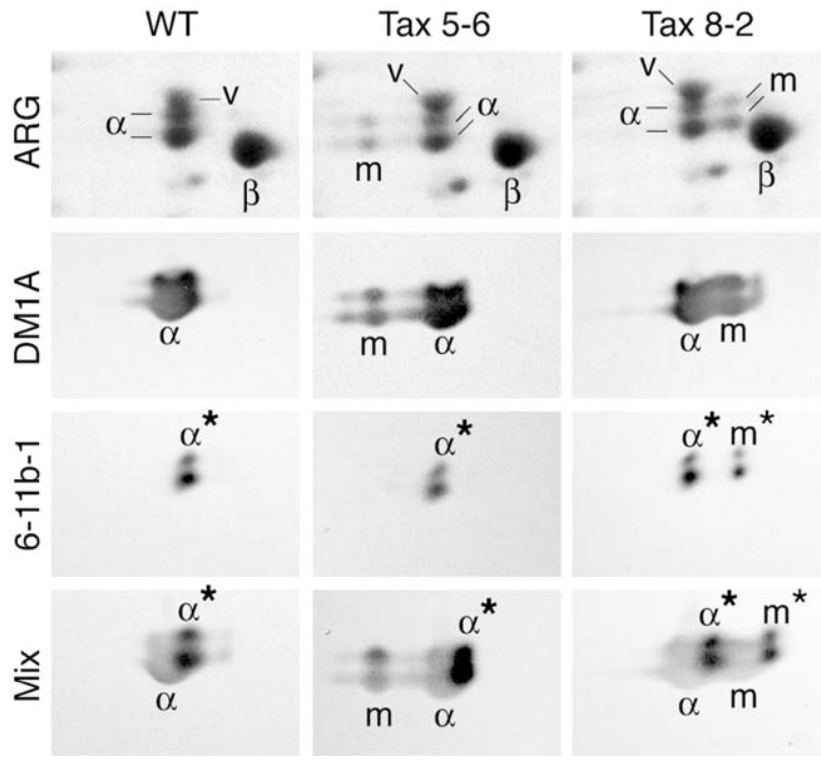

Fig. 6. Mutant tubulin in Tax 5-6 is not acetylated. Wildtype (WT) and paclitaxel resistant Tax 5-6 and Tax 8-2 CHO cell lines (Table I) were metabolically labeled in ${ }^{35} \mathrm{~S}$-methionine and lysed in SDS. Proteins in the lysates were resolved by twodimensional gel electrophoresis and transferred to nitrocellulose membranes. The membranes were exposed to X-ray film (ARG) and stained with antibodies to $\alpha$-tubulin (DM1A), acetylated $\alpha$-tubulin (6-11b-1), or a mixture of the two (Mix). The acidic ends of the gels are oriented to the right and only the tubulin area of the gels are shown. v, vimentin; $\alpha, \alpha$-tubulin; $\beta, \beta$ tubulin; $m$, mutant $\alpha$-tubulin; $\alpha^{*}$, acetylated $\alpha$-tubulin; $\mathrm{m}^{*}$, acetylated mutant $\alpha$-tubulin. Note that by diluting the DM1A antibody in the Mix, it stains the blots much less intensely, allowing the acetylated $\alpha$-tubulin to stand out and create a double labeling effect.

lysine 40 [LeDizet and Piperno, 1987; Piperno et al., 1987]. The isoelectric point of the acetylated tubulin is more acidic as expected for the neutralization of the charge on lysine 40. This shift in isoelectric point can be demonstrated by the mixing experiment in Fig. 6 in which both antibodies were used to stain the western blot simultaneously.

The autoradiogram for Tax 5-6 had the same spots that were seen in the wild-type cell extract, but contained two additional spots representing $\alpha$-tubulin with the E22K mutation migrating at a more basic isoelectric point. The identification of the new spots as $\alpha$-tubulin was confirmed by the reaction with DM1A (Fig. 6). Some additional weaker "spots" on this blot are part of a streak that indicates incomplete focusing of the $\alpha$-tubulin in this particular sample. When a similar blot was probed with the $6-11 \mathrm{~b}-1$ antibody, only the wild-type $\alpha$-tubulin reacted as confirmed by probing a blot with a mixture of the two antibodies. This experiment demonstrated that Tax 5-6 contains the necessary enzymes to carry out acetylation of tubulin, but that the E22K mutation interferes with the acetylation of lysine 40 .
In contrast to Tax 5-6, another mutant, Tax 8-2, produced a mutant protein that reacted with antibody $6-11 \mathrm{~b}-$ 1 (Fig. 6). Tax 8-2 has a K394E mutation in $\alpha$-tubulin that causes the protein to focus at a more acidic isoelectric point. Unlike the mutant protein in Tax 5-6, the Tax 8-2 mutant protein reacted with both the DM1A and 6-11b-1 antibodies demonstrating that it was acetylated at lysine 40 . Screening other mutants with mobility shifts of $\alpha$-tubulin on twodimensional gels in this manner uncovered no additional cell lines with a defect in acetylation.

\section{Discussion}

The results from this study significantly expand the collection of $\alpha$-tubulin mutations found in drug resistant mammalian cells. Several previously published mutations have come from cell lines selected for resistance to drugs that inhibit microtubule assembly, and only one from a cell line resistant to paclitaxel (Table II). All the previous mutations except those for resistance to colcemid and vinblastine were found in cell lines that had undergone multistep selections and may therefore have multiple lesions contributing to the resistance phenotype. For example an S379R substitution in $\alpha$-tubulin reported in paclitaxel resistant A549 cells was found along with altered levels of the microtubule interacting protein stathmin, and the relative contributions of these changes to the mutant phenotype are unknown [Martello et al., 2003]. Moreover, no known mutations in $\alpha$-tubulin have been verified as necessary and sufficient to produce drug resistance using methods such as reversion analysis or transfection of mutant cDNA.

The mutations described in our current studies were found in mutant cell lines derived in single step selections; thus, all the mutations are likely to be responsible for the drug resistance phenotype. In most cases this expectation was verified by selecting revertant cell lines that regained sensitivity to paclitaxel [Schibler and Cabral, 1986] or by recreating the phenotype in wild-type $\mathrm{CHO}$ cells via transfection of cDNA carrying the mutation (e.g., Fig. 2). Paclitaxel resistance was unlikely to be caused by decreased affinity of the drug for tubulin. This conclusion was reached based on the theoretical argument that diminished drug binding is a recessive phenotype that should not appear in diploid cells as well as experimental evidence that mammalian cells with reduced drug binding have been accompanied by a loss of heterozygosity [Giannakakou et al., 1997; Giannakakou et al., 2000; Begaye et al., 2011; Kanakkanthara et al., 2011]. In contrast, our mutant cell lines retain one (genomic mutants) or both (random mutagenesis mutants) wild-type alleles and exhibit properties such as reduced microtubule assembly and paclitaxel dependence for growth that cannot be explained by drug binding effects. The properties of our $\alpha$-tubulin mutants are consistent with the phenotypes of previously described $\beta$-tubulin mutants and suggest a resistance mechanism in 

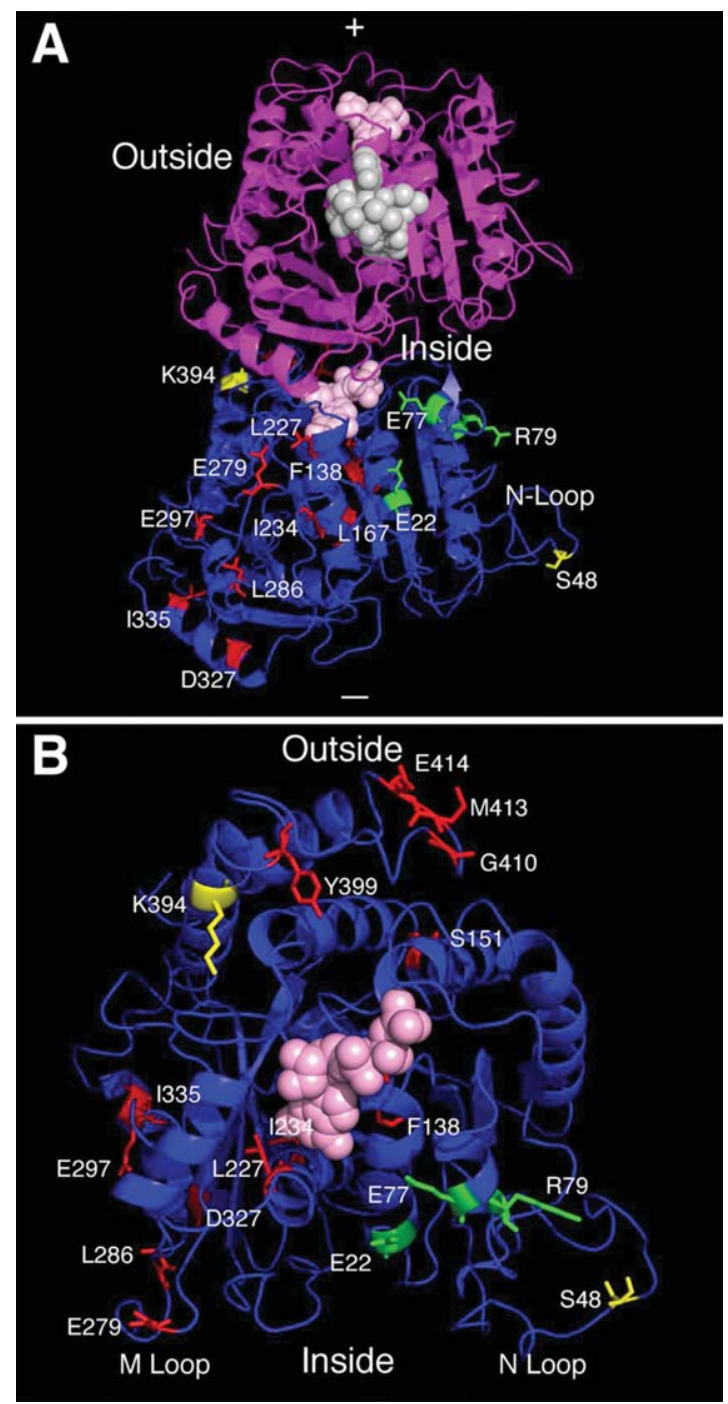

Fig. 7. Distribution of mutations in $\alpha$-tubulin. The structure of an $\alpha \beta$ tubulin heterodimer was created with MacPymol [DeLano, 2005] using the atomic coordinates published as 1TUB in the Protein Data Bank [Nogales et al., 1998]. Blue, $\alpha$-tubulin; magenta, $\beta$-tubulin; pink spheres, guanine nucleotides; gray spheres, docetaxel (an analog of paclitaxel). The locations of genomic mutations are indicated in green and the locations of mutations generated by random mutagenesis are shown in red. Two of the lesions (affecting residues S48 and K394) were found in both genomic and random mutants (see Table I) and are indicated by yellow. The orientation of the heterodimer is shown relative to the + (fast growing) and - (slow growing) ends, as well as to the outside and inside (lumen) of the microtubule. The position of the N-loop (H1/S2 loop) is labeled on the $\alpha$ subunit. (A) lateral view; (B) axial view from the plus end. The $\beta$ subunit was hidden from the axial view to simplify the image. Amino acid substitutions found in the mutant cell lines are labeled.

which the mutations alter microtubule assembly in a way that counteracts the action of the selecting drug [Cabral, 2008; Ganguly and Cabral, 2011]. We previously reported that alterations in $\alpha$-tubulin are as frequent as alterations in $\beta$-tubulin among cell lines selected for resistance to pacli- taxel [Schibler and Cabral, 1986] and the new data obtained with cell lines created by transfection of randomly mutagenized cDNA confirm the involvement of $\alpha$-tubulin mutations in paclitaxel resistance. The data further show that the phenotypes of the mutant cells and the mechanism by which they have acquired resistance are similar for $\alpha$ and $\beta$-tubulin mutants.

One significant difference between the genomic mutations in $\alpha$-tubulin and the mutations identified by random mutagenesis was their distribution. Whereas the genomic mutations were largely restricted to the $\mathrm{N}$-terminal region of $\alpha$-tubulin, the mutations identified by transfection of mutagenized cDNA were distributed throughout the sequence. The reason for this difference is unclear, but we propose that it may result from the constraints imposed on the expression of endogenous genes as opposed to the more heterogeneous expression of transfected cDNAs. For example, CHO cells have two copies of the $\alpha 1$-tubulin gene that together account for about $70 \%$ of $\alpha$-tubulin production [Elliott et al., 1985, 1986]. A mutant allele would then affect about $35 \%$ of the total tubulin. At this level of production, a strong mutation might be so disruptive to microtubule assembly that the cells would be unable to survive under any conditions whereas a weak mutation might be insufficiently disruptive to allow the cells to survive selection in paclitaxel. The transfection of mutagenized cDNAs is free of such restrictions. A strong mutation could be expressed at a low level whereas a weak mutation could be expressed at a high level thus giving each the opportunity to confer resistance yet maintain the viability of the cells in the presence of the drug. Because transfection produces cells with varying levels of expression, the addition of a toxic drug allows cells that produce the right level of mutant protein to survive the selection while those that produce too much or too little are lost. Similar arguments have been made in the case of $\beta$-tubulin where most genomic mutations were found in the $\mathrm{H} 6 / \mathrm{H} 7$ loop of the protein but mutations identified by transfection were distributed throughout the sequence [Yin et al., 2012].

Of all the paclitaxel resistance mutations, only E77 has been reported to form a direct contact with an adjacent subunit in assembled microtubules but many of the altered amino acid residues are close to regions of contact and are likely to affect lateral or longitudinal interactions [Nogales et al., 1999]. This observation is consistent with the conclusion that the mutations produce drug resistance by altering the assembly properties of tubulin. For example, residue S48 was altered in mutants Tax 9-2 and Ptx 12 (Table I). This residue is exposed on the surface of $\alpha$-tubulin and lies in the middle of the N-loop which has been proposed to play a prominent role in lateral interactions between $\alpha$-tubulins on adjacent protofilaments (Fig. 7). Similarly, E279 and L286 are located in the M-loop that appears to interact with the N-loop to form the major lateral contacts between protofilaments [ $\mathrm{Li}$ et al., 2002]. Significantly, 
Table II. Other Drug Resistance Mutations in $\alpha$-Tubulin.

\begin{tabular}{|c|c|c|c|}
\hline Mutation & Phenotype & Location & Reference \\
\hline $\mathrm{A} 12 \mathrm{~S}$ & $\mathrm{Hti}^{\mathrm{R}}$ & Helix 1 & [Loganzo et al., 2004] \\
\hline E55K & $\mathrm{Cmd}^{\mathrm{R}}$ & N-loop ${ }^{a}$ & [Hari et al., 2003] \\
\hline S165P & $\mathrm{Hti}^{\mathrm{R}}$ & H4/S5 loop ${ }^{a}$ & [Poruchynsky et al., 2004] \\
\hline $\mathrm{R} 221 \mathrm{H}$ & $\mathrm{Hti}^{\mathrm{R}}$ & H6/H7 loop ${ }^{b}$ & [Poruchynsky et al., 2004] \\
\hline $\mathrm{H} 283 \mathrm{Y}$ & $\mathrm{Cmd}^{\mathrm{R}}$ & M-loop ${ }^{a}$ & [Hari et al., 2003] \\
\hline S379R & $\operatorname{Ptx}^{\mathrm{R}}$ & Sheet 10 & [Martello et al., 2003] \\
\hline A383V & $\mathrm{Cmd}^{\mathrm{R}}$ & Helix $11^{\mathrm{b}}$ & [Hari et al., 2003] \\
\hline $\mathrm{I} 384 \mathrm{~V}$ & $\mathrm{Hti}^{\mathrm{R}}$ & Helix $11^{\mathrm{b}}$ & [Poruchynsky et al., 2004] \\
\hline R390C & $\mathrm{Vlb}^{\mathrm{R}}$ & Helix $11^{\mathrm{b}}$ & [Hari et al., 2003] \\
\hline
\end{tabular}

mutations in both $\mathrm{N}$ and $\mathrm{M}$ loops have also been identified in colcemid resistant cell lines (Table II) suggesting that alterations that either strengthen or weaken the interprotofilament interactions can produce resistance to drugs with opposing actions on microtubule assembly. Other amino acid substitutions located in structural elements that may affect lateral contacts are indicated in Tables I and II.

Further mutations are predicted to perturb structural elements that form longitudinal contacts within the protofilaments, and these mutations are also indicated in Tables I and II. In addition to E77 that is altered in Tax 11-6, a prominent region of $\alpha$-tubulin encompassing K394 to E414 is altered in Tax 8-2, Ptx 7, Ptx 9, and Ptx 11 (Table I) and is near the intradimer contact with $\beta$-tubulin. These mutations could potentially alter the conformation of the heterodimer and lead to weaker interdimer and lateral interactions in the microtubule. More buried residues such as L167, F138, and the core helix 7 residues L227 and I234 could also be acting by altering the conformation of tubulin. The widely distributed mutations identified by random mutagenesis indicate that diverse regions involved in microtubule assembly can play a role in altering sensitivity to paclitaxel and related drugs.

One unusual mutation was discovered in cell line Tax 5-6. The E22K mutation in these cells inhibited the ability of the altered $H A \alpha 1$-tubulin to be acetylated at lysine40. This defect did not arise from an alteration in the acetylation machinery because the co-expressed wild-type $\alpha$-tubulin was acetylated normally. Instead, it seems likely that the E22K alteration may affect the binding of the acetyltransferase or it may alter the conformation of the $\alpha$-tubulin in such a way as to make it a poor substrate. The significance of tubulin acetylation is still controversial, but most studies indicate that it does not play a major role in microtubule assembly or stability. Because polymerized tubulin is the substrate for the acetyltransferase, acetylation is generally recognized as a marker for the longevity of the microtubule; i.e., "older" microtubules are more heavily acetylated than newly formed microtubules [Janke and Bulinski, 2011; Westermann and Weber, 2003]. Consistent with these observations, we found no unusual phenotype in Tax 5-6 in terms of its proliferation, microtubule assembly, or drug sensitivity compared to other paclitaxel resistant mutants with normal tubulin acetylation.

Finally, we wish to point out that similar microtubule defects may underlie multiple phenotypes; for example, a growing list of $\alpha$ - and $\beta$-tubulin mutations has recently been shown to cause or contribute to a number of neurological disorders including lissencephaly, polymicrogyria, and cerebellar hypoplasia [Tischfield et al., 2011]. We previously reported that $\beta$-tubulin mutations we and others have found in drug resistant cell lines have also been reported in developmental brain disorders [Yin et al., 2012]. We now report that a similar situation occurs with $\alpha$-tubulin mutations (Table III). Although the number of $\alpha$-tubulin mutations available for comparison is more limited, we have already seen that an E55K mutation identified in a colcemid and vinblastine resistant cell line (Table II) was reported in a patient with lissencephaly (Table III), an R390C mutation identified in a vinblastine resistant cell line (Table II) has been reported in a patient with polymicrogyria (Table III), and an L286P mutation that confers resistance to paclitaxel (Table I) coincides with an L286F mutation reported in a patient with lissencephaly (Table III). In addition, several more mutations causing brain dysgenesis are adjacent or lie very close to mutations that cause drug resistance (indicated in Table III). These observations suggest that mutations affecting microtubule assembly can produce pleiotropic effects encompassing both drug 


\begin{tabular}{|c|c|c|c|c|c|}
\hline Mutation & Location & Reference & Mutation & Location & Reference \\
\hline I5L & S1 & 1 & A270T & S7 & 3 \\
\hline $\mathrm{E} 55 \mathrm{~K}^{\mathrm{a}}$ & N-loop & 2 & $\mathrm{~L} 286 \mathrm{~F}^{\mathrm{a}}$ & M-loop & 5 \\
\hline L92V & S3 & 3 & V303G & $\mathrm{H} 9 / \mathrm{S} 8$ & 7 \\
\hline V137D ${ }^{b}$ & S4 & 3 & $\mathrm{~N} 329 \mathrm{~S}^{\mathrm{c}}$ & $\mathrm{H} 10$ & 3 \\
\hline Y161H & $\mathrm{H} 4$ & 4 & $\mathrm{M} 377 \mathrm{~V}^{\mathrm{c}}$ & S10 & 3 \\
\hline I188L & $\mathrm{H} 5$ & 5 & $\mathrm{R} 390 \mathrm{C}^{\mathrm{a}}$ & H11 & 3,4 \\
\hline Y210C & H6 & 1 & L397P ${ }^{c}$ & H11 & 8 \\
\hline $\mathrm{D} 218 \mathrm{Y}^{\mathrm{c}}$ & $\mathrm{H} 6 / \mathrm{H} 7$ & 3 & $\mathrm{R} 402 \mathrm{C}, \mathrm{H}, \mathrm{L}^{\mathrm{c}}$ & H11/H11' & $2,3,5$ \\
\hline$V 235 \mathrm{~L}^{\mathrm{b}}$ & $\mathrm{H} 7$ & 4 & S419L & H12 & 5 \\
\hline $\mathrm{I} 238 \mathrm{~V}$ & $\mathrm{H} 7$ & 6 & $\mathrm{R} 422 \mathrm{C}, \mathrm{H}$ & H12 & $2,3,8$ \\
\hline P263T & $\mathrm{H} 8 / \mathrm{S} 7$ & 5 & M425K & $\mathrm{H} 12$ & 3 \\
\hline R264C & $\mathrm{H} 8 / \mathrm{S} 7$ & 5 & G436R & Disordered $^{\mathrm{d}}$ & 8 \\
\hline 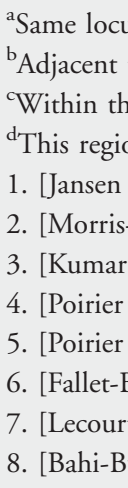 & $\begin{array}{l}\text {-esistance mu } \\
\text { istance muta } \\
\text { ids of a dru, } \\
\text { arboxyl term } \\
\text { t al., 2008] } \\
\\
2008 \text { ] } \\
10] \\
2008 \text { ] }\end{array}$ & $\begin{array}{l}\text { nutation. } \\
\text { lin is disorder }\end{array}$ & tal structure. & & \\
\hline
\end{tabular}

resistance and tissue formation and function. It is likely that further overlaps will be found in future studies.

\section{Materials and Methods}

\section{Materials}

CHO tTA puro 6.6a cells expressing a tetracycline regulated transactivator $(\mathrm{tTA})$ were maintained at $37^{\circ} \mathrm{C}$ in alpha modified minimum essential medium $(\alpha M E M)$ supplemented with 5\% fetal bovine serum (Atlanta Biologicals), $50 \mathrm{U} \mathrm{ml}^{-1}$ penicillin, $50 \mu \mathrm{g} \mathrm{ml}^{-1}$ streptomycin (Invitrogen), $10 \mu \mathrm{g} \mathrm{ml}^{-1}$ puromycin, and $1 \mu \mathrm{g} \mathrm{ml}^{-1}$ tetracycline [Gonzalez-Garay et al., 1999]. CHO C $\alpha 1$ cDNA (GeneBank $^{\mathrm{TM}}$ accession no. M12252.1) was cloned into pTOPneo which contains a minimal CMV promoter driven by seven upstream copies of the tet operator [Gossen and Bujard, 1992; Gonzalez-Garay et al., 1999]. The cDNA was engineered to encode a nine amino acid hemagglutinin antigen (HA) epitope tag (YPYDVPDYA) at the C-terminal end of the protein to create the plasmid pTOPHA $\alpha 1$. Chemicals and tissue culture media were from Sigma-Aldrich unless otherwise stated.

\section{Random Mutagenesis and Selection of Paclitaxel Resistant Cell Lines}

A random pool of $H A \alpha 1$-tubulin mutations were generated using PCR reactions with an error-prone Taq polymerase (Invitrogen, Carlsbad, CA) and two plasmid sequence primers (pTOPF2, 5'-GAT CCC CCA TTA TTG AAG CA$3^{\prime}$ and pTOPR2, 5'-CAG AAG CCA TAG AGC CCA CC- $\left.3^{\prime}\right)$ that span the coding and regulatory sequences of the cDNA. The Taq polymerase has an error rate of $8 \times$ $10^{-6}$; after 20 cycles under normal conditions, $16 \%$ of the PCR products are expected to contain random mutations with no hot spots (see the product manual). We obtained a broad range of mutations by combining reactions from 30 , 35, and 40 cycles. The mixed linear DNAs were purified using a QIAprep 8 Miniprep Kit (Qiagen, Valencia, CA) and then transfected into $\mathrm{CHO}$ tTApuro 6.6a cells using Lipofectamine (Invitrogen) as described elsewhere [Gonzalez-Garay et al., 1999]. Transfected cells were reseeded into six-well dishes, grown to 50\% confluence, and treated with $300 \mathrm{ng} \mathrm{ml}^{-1}$ paclitaxel in the absence of tetracycline to allow expression of the transfected DNA. After 14 days, visible colonies were isolated and grown in 24-well dishes 
in the continued presence of $300 \mathrm{ng} \mathrm{ml}^{-1}$ paclitaxel. As an initial test for whether resistance was caused by the expression of exogenous $\alpha$-tubulin, cells were seeded into 24-well dishes containing $300 \mathrm{ng} \mathrm{ml}^{-1}$ paclitaxel in the presence and absence of $1 \mu \mathrm{g} \mathrm{ml}^{-1}$ tetracycline and incubated for 7 days. Surviving colonies were stained by removing the medium, rinsing the wells with PBS, and adding $0.1 \%$ methylene blue for at least $1 \mathrm{~h}$ [Cabral et al., 1980]. The wells were rinsed with water to remove excess stain and digital photographs were taken.

\section{Immunofluorescence}

Cells grown on sterile glass coverslips in $\alpha$ MEM without tetracycline were rinsed briefly in $\mathrm{PBS}$, pre-extracted with microtubule buffer (MTB) (20 mM Tris- $\mathrm{HCl}, \mathrm{pH} 6.8,1$ $\mathrm{mM} \mathrm{MgCl} 2,2 \mathrm{mM}$ EGTA, $0.5 \% \mathrm{NP}-40$ and $4 \mu \mathrm{g} \mathrm{ml}^{-1}$ paclitaxel) for 2-3 min on ice, and fixed in methanol at $-20^{\circ} \mathrm{C}$ for at least $20 \mathrm{~min}$. The fixed cells were incubated with mouse monoclonal anti- $\alpha$-tubulin antibody DM1A (1:100, Sigma-Aldrich) and/or affinity purified rabbit polyclonal anti-HA antibody (1:50, Bethyl Laboratories, Montgomery, TX) for $30-60 \mathrm{~min}$ at $37^{\circ} \mathrm{C}$ in a humid chamber. After rinsing in PBS, the cells were stained with 1:50 dilutions of Alexa 594-conjugated goat anti-mouse IgG and/or Alexa 488-conjugated goat anti-rabbit IgG (Invitrogen) and $1 \mu \mathrm{g} \mathrm{ml}^{-1}$ DAPI. The microtubules were visualized using an Optiphot microscope equipped with epifluorescence and a $60 \times$ objective (Nikon, Melville, NY). Images were captured using a Magnafire digital camera (Optronics, Goleta, CA).

\section{$\alpha$-Tubulin Sequencing}

Genomic DNA was prepared by lysing cells in a buffer containing $20 \mathrm{mM}$ Tris- $\mathrm{HCl}(\mathrm{pH}$ 8.0), $50 \mathrm{mM} \mathrm{KCl}, 2.5 \mathrm{mM}$ $\mathrm{MgCl}_{2}$, and $0.5 \%$ Tween 20. Proteinase $\mathrm{K}$ was added to a final concentration of $0.1 \mathrm{mg} \mathrm{ml}^{-1}$ and the lysate was heated to $55^{\circ} \mathrm{C}$ for $45 \mathrm{~min}$. Enzymatic activity was inactivated at $100^{\circ} \mathrm{C}$ for $10 \mathrm{~min}$ and the lysate was stored at $-20^{\circ} \mathrm{C}$ overnight. For the mutants derived by transfection, PCR reactions were carried out using a $5^{\prime}$-UTR forward

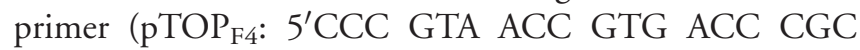
TGT CTG $\mathrm{C}^{\prime}$ ) and a pTOP reverse complementary primer $\left(\mathrm{pTOP}_{\mathrm{R}}\right.$ : 5'CTA GAA GGC ACA GTC GAG GCT3'). The PCR-amplified products were sequenced with three primers: (1) a $5^{\prime}$-UTR forward primer (pTOP ${ }_{F 5}$ : 5'CTG TCT GCT TTT GTC ACC3'), (2) a forward primer immediately before the 190th amino acid codon of the $\alpha 1$-tubulin cDNA sequence (C $\alpha 1$ 190 $0_{\mathrm{F}}: 5^{\prime} \mathrm{CCC}$ TAC AAC TCC ATC CTC ACC ACC CAC3'), and (3) a reverse primer complementary to the HA tag (HAtagR: 5'CTG TCT GCT TTT GTC ACC 3 '). For mutants derived by classical genetics, exons 2, 3, and 4 were amplified by PCR using intron primers specific for C $\alpha 1$ (GenBank Accession No. AY173017). All PCR-amplified products were sequenced by the DNA Sequencing Core Facility (Baylor College of Medicine, Houston, TX).

\section{Confirmation of Paclitaxel Resistance Mutations}

Point mutations identified by sequencing were introduced into pTOPHA $\alpha 1$ using the QuickChange site-directed mutagenesis kit from Invitrogen. CHO tTA puro 6.6a cells were transfected with the mutant plasmid and the ability of the transfected cells to produce colonies in normally toxic concentrations of paclitaxel was monitored. To enrich for transfected cells that expressed the mutant cDNAs, the transfectants were grown in G418 plus $1 \mu \mathrm{g} \mathrm{ml}^{-1}$ tetracycline for 10 days. The G418 resistant cells were trypsinized, seeded in duplicate wells of six-well dishes containing $300 \mathrm{nM}$ paclitaxel (one well with and one well without 1 $\mu \mathrm{g} \mathrm{ml}^{-1}$ tetracycline), and allowed to grow for 10 days. A third well containing 50-fold fewer cells was grown for 7 days in $\alpha$ MEM with $1 \mu \mathrm{g} \mathrm{ml}^{-1}$ tetracycline but no paclitaxel. This third well produced colonies that could be used to estimate the number of viable cells that were inoculated into each well. At the end of the experiment the plates were stained with methylene blue, rinsed with water, and photographed with a digital camera.

\section{Antibodies and Western Blots}

Transfected cells were grown to $80-100 \%$ of confluence in 24 -well dishes and lysed in 1\% SDS. Proteins were precipitated by adding 5 vol. of acetone, centrifuging for $5 \mathrm{~min}$ at $12,000 \times g$, and resuspending the pellet in $100 \mu \mathrm{l}$ of sample buffer $(0.0625 \mathrm{M}$ Tris-HCl, pH6.8, 2.5\% SDS, 5\% 2-mercaptoethanol, $10 \%$ glycerol). Proteins were separated on $7.5 \%$ polyacrylamide SDS minigels and transferred to nitrocellulose membranes (Schleicher and Schuell, Keene, $\mathrm{NH}$ ). After blocking the membranes in PBST (PBS with $0.05 \%$ Tween 20 ) containing $3 \%$ dry milk, they were incubated in a 1:2,000 dilution of monoclonal antibody DM1A (Sigma-Aldrich) specific for $\alpha$-tubulin. A 1:2000 dilution of anti-actin antibody C4 (Chemicon International, Temecula, CA) was also added as a loading control. The membranes were incubated for 45-60 min at room temperature and then washed three times in PBST for $10 \mathrm{~min}$ each. Bands were detected by incubating the membranes for $30-45 \mathrm{~min}$ in a 1:2000 dilution of peroxidase-conjugated goat anti-mouse IgG (Sigma-Aldrich) and washing three times in PBST. Finally, SuperSignal West Pico chemiluminescent substrate (Thermo Fisher Scientific, Rockford, IL) was added and the membrane was exposed to X-ray film (Phenix Research Products, Candler, NC).

\section{Quantification of Microtubule Polymer}

Cells were grown overnight in triplicate wells of 24-well dishes containing $\alpha$ MEM and lysed in $100 \mu \mathrm{l}$ MTB [Minotti et al., 1991]. Cell remnants were scraped from the wells and transferred into $1.5 \mathrm{ml}$ microcentrifuge tubes. The 
wells were rinsed with another $100 \mu \mathrm{l}$ MTB and this was combined with the corresponding lysate. To solubilize any residue, $100 \mu \mathrm{l}$ of $1 \%$ SDS was added to the wells and kept for later. The lysates were briefly mixed and centrifuged at $12,000 \times g$ for $15 \mathrm{~min}$ at $4^{\circ} \mathrm{C}$. The supernatants carrying the unpolymerized tubulin were transferred to fresh tubes. The pellets containing the polymerized tubulin were resuspended in $50 \mu \mathrm{l}$ water for $20-30 \mathrm{~min}$ and combined with the residues solubilized in SDS from the corresponding wells. To each sample (supernatant and pellet) $10 \mu \mathrm{l}$ of a bacterial lysate containing a GST-tagged $\alpha$-tubulin was also added as a quantitative control for possible protein losses during subsequent steps. Proteins were precipitated using 5 vol. of acetone and resuspended in $100 \mu \mathrm{l} 1 \times$ sample buffer. Equal volumes of samples were resolved on $7.5 \%$ polyacrylamide SDS minigels (BIORAD) and transferred to nitrocellulose membranes (Schleicher and Schuell). Blots were incubated with mouse monoclonal antibodies to $\alpha$-tubulin (DM1 $\alpha$, Sigma) followed by an Alexa 647-conjugated goat anti-mouse secondary antibody (Invitrogen) as described above. Bands were detected with a Storm imager (Molecular Dynamics, Sunnyvale, CA) and quantified using Image J. Relative amounts of microtubule polymer were determined by calculating the $\alpha$-tubulin to GST- $\alpha$-tubulin ratio for the supernatant (free tubulin) and pellet (polymerized tubulin) from each sample and then calculating the percentage of total tubulin that is in the polymer state by dividing the ratio from the pellet by the sum of the ratios from the pellet and supernatant fractions and multiplying by 100 .

\section{Two-dimensional Gel Electrophoresis}

Cells were metabolically labeled for $1 \mathrm{~h}$ in methionine-free minimum essential medium (Sigma-Aldrich) containing $25 \mu \mathrm{Ci} \mathrm{ml}{ }^{-1}$ TRAN $^{35}$ S-LABEL (MP Biomedicals, Solon, $\mathrm{OH})$. Proteins were then solubilized in $1 \%$ SDS, precipitated in 5 vol. of cold ethanol, and resolubilized in $8 \mathrm{M}$ urea, 5\% 2-mercaptoethanol, 2\% Triton X-100, $5 \mathrm{mM}$ Tris-hydrochloride, $\mathrm{pH}$ 6.8. The proteins were separated by two-dimensional gels and transferred to nitrocellulose membranes using published procedures [Cabral and Gottesman, 1978; Cabral and Schatz, 1979]. The detection of $\alpha$-tubulin on the membranes was accomplished using a 1:2000 dilution of monoclonal antibody DM1A (SigmaAldrich) that specifically recognizes $\alpha$-tubulin in a wide range of organisms. The specific identification of acetylated $\alpha$-tubulin was carried out using a 1:2000 dilution of monoclonal antibody 6-11b-1 (Sigma-Aldrich) that recognizes $\alpha$-tubulin acetylated at residue lysine-40 [LeDizet and Piperno, 1987; Piperno et al., 1987]. The protein spots were visualized using a peroxidase conjugated goat antimouse IgG (1:2000 dilution, Sigma-Aldrich) and SuperSignal West Pico chemiluminescent substrate (Thermo Fisher Scientific). To detect both acetylated and total $\alpha$-tubulin simultaneously on the same blots, both primary antibodies were mixed but the DM1A was further diluted $(1: 50,000)$ to give each antibody a unique staining appearance.

\section{Acknowledgments}

This work was supported by grant CA85935 from the National Institutes of Health to FC. The authors report no conflict of interest.

\section{References}

Abraham I, Marcus M, Cabral F, Gottesman MM. 1983. Mutations in $\alpha$ - and $\beta$-tubulin affect spindle formation in Chinese hamster ovary cells. J Cell Biol 97:1055-1061.

Bahi-Buisson N, Poirier K, Boddaert N, Saillour Y, Castelnau L, Philip N, Buyse G, Villard L, Joriot S, Marret S, et al. 2008. Refinement of cortical dysgeneses spectrum associated with TUBA1A mutations. J Med Genet 45:647-653.

Begaye A, Trostel S, Zhao Z, Taylor RE, Schriemer DC, Sackett DL. 2011. Mutations in the beta-tubulin binding site for peloruside A confer resistance by targeting a cleft significant in side chain binding. Cell Cycle 10:3387-3396.

Bhattacharya R, Cabral F. 2004. A ubiquitous $\beta$-tubulin disrupts microtubule assembly and inhibits cell proliferation. Mol Biol Cell 15:3123-3131.

Boggs B, Cabral F. 1987. Mutations affecting assembly and stability of tubulin: Evidence for a non-essential $\beta$-tubulin in $\mathrm{CHO}$ cells. Mol Cell Biol 7:2700-2707.

Cabral F. 1983. Isolation of Chinese hamster ovary cell mutants requiring the continuous presence of taxol for cell division. J Cell Biol 97:22-29.

Cabral F. 2001. Factors determining cellular mechanisms of resistance to antimitotic drugs. Drug Resistance Updates 3:1-6.

Cabral F. 2008. Mechanisms of resistance to drugs that interfere with microtubule assembly. In: Fojo AT, editor. Cancer Drug Discovery and Development: The Role of Microtubules in Cell Biology, Neurobiology, and Oncology. Totowa, NJ: Humana Press. pp 337-356.

Cabral F, Gottesman MM. 1978. The determination of similarities in amino acid composition among proteins separated by twodimensional gel electrophoresis. Anal Biochem 91:548-556.

Cabral F, Schatz G. 1979. High resoultion one- and twodimensional electrophoretic analysis of mitochondrial membrane proteins. Methods Enzymol 56:602-613.

Cabral F, Sobel ME, Gottesman MM. 1980. CHO mutants resistant to colchicine, colcemid or griseofulvin have an altered $\beta$-tubulin. Cell 20:29-36.

Cabral F, Wible L, Brenner S, Brinkley BR. 1983. Taxol-requiring mutant of Chinese hamster ovary cells with impaired mitotic spindle assembly. J Cell Biol 97:30-39.

Cabral F, Brady RC, Schibler MJ. 1986. A mechanism of cellular resistance to drugs that interfere with microtubule assembly. Ann N Y Acad Sci 466:745-756.

DeLano WL. 2005. Macpymol: A Pymol-Based Molecular Graphics Application for Mac OSX. South San Francisco, CA: DeLano Scientific LLC.

Dumontet C, Jordan MA. 2010. Microtubule-binding agents: A dynamic field of cancer therapeutics. Nat Rev Drug Discov 9:790 803. 
Elliott EM, Okayama H, Sarangi F, Henderson G, Ling V. 1985. Differential expression of three $\alpha$-tubulin genes in Chinese hamster ovary cells. Mol Cell Biol 5:236-241.

Elliott EM, Henderson G, Sarangi F, Ling V. 1986. Complete sequence of three $\alpha$-tubulin cDNAs in Chinese hamster ovary cells: Each encodes a distinct $\alpha$-tubulin isoprotein. Mol Cell Biol 6:906913.

Fallet-Bianco C, Loeuillet L, Poirier K, Loget P, Chapon F, Pasquier L, Saillour Y, Beldjord C, Chelly J, Francis F. 2008. Neuropathological phenotype of a distinct form of lissencephaly associated with mutations in TUBA1A. Brain 131:2304-2320.

Ganguly A, Cabral F. 2011. New insights into mechanisms of resistance to microtubule inhibitors. Biochim Biophys Acta 1816: $164-171$.

Ganguly A, Yang H, Cabral F. 2010. Paclitaxel dependent cell lines reveal a novel drug activity. Mol Cancer Ther 9:2914-2923.

Ganguly A, Yang H, Cabral F. 2011. Overexpression of mitotic centromere-associated kinesin stimulates microtubule detachment and confers resistance to paclitaxel. Mol Cancer Ther 10:929-937.

Giannakakou P, Sackett DL, Kang Y-K, Zhan Z, Buters JTM, Fojo T, Poruchynsky MS. 1997. Paclitaxel-resistant human ovarian cancer cells have mutant $\beta$-tubulins that exhibit impaired paclitaxel-driven polymerization. J Biol Chem 272:17118-17125.

Giannakakou P, Gussio R, Nogales E, Downing KH, Zaharevitz D, Bollbuck B, Poy G, Sackett D, Nicolaou KC, Fojo T. 2000. A common pharmacophore for epothilone and taxanes: Molecular basis for drug resistance conferred by tubulin mutations in human cancer cells. Proc Natl Acad Sci USA 97:2904-2909.

Gonzalez-Garay ML, Chang L, Blade K, Menick DR, Cabral F. 1999. A $\beta$-tubulin leucine cluster involved in microtubule assembly and paclitaxel resistance. J Biol Chem 274:23875-23882.

Gossen M, Bujard H. 1992. Tight control of gene expression in mammalian cells by tetracycline-responsive promoters. Proc Natl Acad Sci USA 89:5547-5551.

Hari M, Wang Y, Veeraraghavan S, Cabral F. 2003. Mutations in $\alpha$ - and $\beta$-tubulin that stabilize microtubules and confer resistance to colcemid and vinblastine. Mol Cancer Ther 2:597-605.

Huzil JT, Chen K, Kurgan L, Tuszynski JA. 2007. The roles of beta-tubulin mutations and isotype expression in acquired drug resistance. Cancer Inform 3:159-181.

Janke C, Bulinski JC. 2011. Post-translational regulation of the microtubule cytoskeleton: Mechanisms and functions. Nat Rev Mol Cell Biol 12:773-786.

Jansen AC, Oostra A, Desprechins B, De Vlaeminck Y, Verhelst H, Regal L, Verloo P, Bockaert N, Keymolen K, Seneca S, et al. 2011. TUBA1A mutations cause wide spectrum lissencephaly (smooth brain) and suggest that multiple neuronal migration pathways converge on alpha tubulins. Neurology 76:988-992.

Jordan MA, Wilson L. 2004. Microtubules as a target for anticancer drugs. Nat Rev 4:253-265.

Kanakkanthara A, Wilmes A, O'Brate A, Escuin D, Chan A, Gjyrezi A, Crawford J, Rawson P, Kivell B, Northcote PT, et al. 2011. Peloruside- and laulimalide-resistant human ovarian carcinoma cells have betaI-tubulin mutations and altered expression of betaII- and betaIII-tubulin isotypes. Mol Cancer Ther 10:14191429.

Keating TJ, Peloquin JG, Rodionov VI, Momcilovic D, Borisy GG. 1997. Microtubule release from the centrosome. Proc Natl Acad Sci USA 94:5078-5083.

Kumar RA, Pilz DT, Babatz TD, Cushion TD, Harvey K, Topf M, Yates L, Robb S, Uyanik G, Mancini GMS, et al. 2010. TUBA1A mutations cause wide spectrum lissencephaly (smooth brain) and suggest that multiple neuronal migration pathways converge on alpha tubulins. Hum Mol Gen 19:2817-2827.

Kung AL, Sherwood SW, Schimke RT. 1990. Cell line-specific differences in the control of cell cycle progression in the absence of mitosis. Proc Natl Acad Sci USA 87:9553-9557.

Lecourtois M, Poirier K, Friocourt G, Jaglin X, Goldenberg A, Saugier-Veber P, Chelly J, Laquerriere A. 2010. Human lissencephaly with cerebellar hypoplasia due to mutations in TUBA1A: Expansion of the foetal neuropathological phenotype. Acta Neuropathol 119:779-789.

LeDizet M, Piperno G. 1987. Identification of an acetylation site of Chlamydomonas $\alpha$-tubulin. Proc Natl Acad Sci USA 84:57205724.

Li H, DeRosier DJ, Nicholson WV, Nogales E, Downing KH. 2002. Microtubule structure at $8 \AA$ resolution. Structure 10:13171328.

Loganzo F, Hari M, Annable T, Tan X, Morilla DB, Musto S, Zask A, Kaplan J, Minnick AAJ, May MK, et al. 2004. Cells resistant to HTI-286 do not overexpress P-glycoprotein but have reduced drug accumulation and a point mutation in alpha-tubulin. Mol Cancer Ther 3:1319-1327.

Martello LA, Verdier-Pinard P, Shen H-J, He L, Torres K, Orr GA, Horwitz SB. 2003. Elevated levels of microtubule destabilizing factors in a taxol-resistant/dependent A549 cell line with an $\alpha$-tubulin mutation. Cancer Res 63:1207-1213.

Minotti AM, Barlow SB, Cabral F. 1991. Resistance to antimitotic drugs in Chinese hamster ovary cells correlates with changes in the level of polymerized tubulin. J Biol Chem 266:3987-3994.

Mitchison T, Kirschner MW. 1984. Dynamic instability of microtubules. Nature 312:237-242.

Morris-Rosendahl DJ, Najm J, Lachmeijer AM, Sztriha L, Martins M, Kuechler A, Haug V, Zeschnigk C, Martin P, Santos M. 2008. Refining the phenotype of alpha-1 $\alpha$-tubulin (TUB1A) mutation in patients with classical lissencephaly. Clin Genet 74:425-433.

Nogales E, Wolf SG, Downing KH. 1998. Structure of the $\alpha \beta$ tubulin dimer by electron crystallography. Nature 391:199-203.

Nogales E, Whittaker M, Milligan RA, Downing KH. 1999. Highresolution model of the microtubule. Cell 96:79-88.

Piperno G, LeDizet M, Chang X. 1987. Microtubules containing acetylated alpha tubulin in mammalian cells in culture. J Cell Biol 104:289-302.

Poirier K, Keays DA, Francis F, Saillour Y, Bahi N, Manouvrier S, Fallet-Bianco C, Pasquier L, Toutain A, Tuy FP, et al. 2007. Large spectrum of lissencephaly and pachygyria phenotypes resulting from de novo missense mutations in tubulin alpha $1 \mathrm{~A}$ (TUBA1A). Hum Mutat 28:1055-1064.

Poirier K, Saillour Y, Fourniol F, Francis F, Souville I, Valence S, Desguerre I, Marie Lepage J, Boddaert N, Line Jacquemont M, et al. 2013. Expanding the spectrum of TUBA1A-related cortical dysgenesis to polymicrogyria. Eur J Hum Genet 21:381-385.

Poruchynsky MS, Kim JH, Nogales E, Annable T, Loganzo F, Greenberger LM, Sackett DL, Fojo T. 2004. Tumor cells resistant to a microtubule-depolymerizing hemiasterlin analogue, HTI-286, have mutations in alpha- or beta-tubulin and increased microtubule stability. Biochemistry 43:13944-13954.

Schibler M, Cabral F. 1986. Taxol-dependent mutants of Chinese hamster ovary cells with alterations in $\alpha$ - and $\beta$-tubulin. J Cell Biol 102:1522-1531.

Sheir-Neiss G, Lai MH, Morris NR. 1978. Identification of a gene for $\beta$-tubulin in Aspergillus nidulans. Cell 15:639-647. 
Thomas JH, Neff NF, Botstein D. 1985. Isolation and characterization of mutations in the beta-tubulin gene of Saccharomyces cerevisiae. Genetics 112:715-734.

Tischfield MA, Cederquist GY, Gupta MLJ, Engle EC. 2011. Phenotypic spectrum of the tubulin-related disorders and functional implications of disease-causing mutations. Curr Opin Genet Dev 21:286-294.

Wang Y, Yin S, Blade K, Cooper G, Menick DR, Cabral F. 2006. Mutations at Leucine 215 of $\beta$-tubulin affect paclitaxel sensitivity by two distinct mechanisms. Biochemistry 45:185-194.
Westermann S, Weber K. 2003. Post-translational modifications regulate microtubule function. Nat Rev Mol Cell Biol 4:938-947.

Yang H, Ganguly A, Cabral F. 2010. Inhibition of cell migration and cell division correlates with distinct effects of microtubule inhibiting drugs. J Biol Chem 285:32242-32250.

Yin S, Bhattacharya R, Cabral F. 2010. Human mutations that confer paclitaxel resistance. Mol Cancer Ther 9:327-335.

Yin S, Zeng C, Hari M, Cabral F. 2012. Random mutagenesis of $\beta$-tubulin defines a set of dispersed mutations that confer paclitaxel resistance. Pharm Res 29:2994-3006. 